\title{
Hipótesis sobre el origen etimológico de la palabra dikē: la analogía del horizonte
}

\section{Hypothesis about the etymology of the word díkē: the analogy of the horizon (or skyline)}

\author{
Maria Antonietta SALAmONE \\ (Universidad Complutense de Madrid)
}

Recibido: 17/09/2012

Aceptado: 19/03/2013

\section{Resumen}

Objeto del presente artículo es demostrar la vinculación filológica entre la justicia, el derecho y la igualdad en el antiguo idioma griego o, que es lo mismo, la vinculación filosófica entre la ética, la política y la economía. Es interesante, pues, examinar el origen etimológico de la palabra dikē que procede de la raíz sánscrita diś-(dik) y hace referencia más que al concepto genérico de «línea recta», al concepto especifico y astronómico de «línea del horizonte» que divide aparentemente el cosmos en dos partes iguales, la tierra y el cielo, significando la misma idea de igualdad la cual debe servir de regla para la norma justa y la perfección ética. Según mi análisis, además, el mismo Platón pudo haber utilizado la analogía de la línea del horizonte para explicar su cosmológica Doctrina de las Ideas.

Palabras clave: etimología, dikē, justicia, línea del horizonte, igualdad, Platón, cosmología, metafísica.

\begin{abstract}
The object of this paper is to demonstrate the philological relation between justice, law and equality in ancient Greek or, that is the same, the philosophical relation between ethics, politics and economics. Actually it is interesting to examine the etymology of the word dike which derives from the Sanskrit diś-(dik) and it refers more than to the generic idea of the «straight line» to the specific and astronomical concept of the «horizon (or skyline)», the apparent line that separates the cosmos into two equal parts, the earth from the sky, meaning the same idea of equality
\end{abstract}


which should be a rule of just law and ethical perfection. Moreover, according to my hypothesis Plato may have used the analogy of the horizon to explain his cosmological Doctrine of Ideas.

Keywords: Etymology, Díkē, Justice, Horizon (Skyline), Equality, Plato, Cosmology, Metaphysic.

\section{La justicia anclada cósmico-teológicamente: su función ordenadora e igualitaria frente a la hýbris}

La justicia propiamente dicha se aplica a la acción humana y más precisamente a la acción de un sujeto en relación con los demás. Y puesto que las relaciones jurídicas se refieren a las relaciones intersubjetivas, a veces justicia y derecho se consideran como sinónimos. Sin embargo la justicia tiene además de un significado jurídico un significado también moral, como criterio o juicio de valor autónomo superior también a las leyes positivas, de manera que se puede levantar la cuestión si estas sean justas o injustas. En un sentido absoluto, el predicado justicia se atribuye primariamente a la divinidad para denotar la infalible perfección de su voluntad que fundamenta la norma del genero humano. Este concepto predomina en los tiempos antiquísimos, especialmente en el mundo hebraico-cristiano expresándose claramente tanto en el Antiguo Testamento (por ejemplo Deuteronomio, XXXII, 4; Salmos, VII, 12) como en el Nuevo (especialmente en las Epístolas de San Pablo a los Romanos, I, 17; II, 2; III 21-26). Es evidente que según este concepto no se hace distinción entre derecho y moral, porque la legislación divina es omnicomprensiva. Así que, por lo que se refiere a las acciones humanas, se consideran deberes de justicia tanto la oración y la celebración de los días de fiesta como, por ejemplo, el no matar y el no robar; el hombre justo es el que cumple rectamente todos estos deberes, y justicia significa en este sentido virtud y perfección moral en general. Al mismo tiempo, sin embargo, en el mundo antiguo aparece otro significado más especifico de la justicia -el de igualdad- que encontramos muy claramente en el Antiguo Testamento, como por ejemplo en el célebre juicio del Rey Salomón donde se cuenta que: "Entonces ordenó el Rey: 'Traedme una espada'. Presentaron la espada al Rey y este sentenció: Cortad el niño vivo en dos partes y dad mitad a una y mitad a otra." (Reyes, III, 25-26)1. Esta misma función igualitaria de la justicia aparece también en el pensamiento griego, como el que se expresa en los poemas de Homero y Hesíodo; en la literatura arcaica, en efecto, la justicia divina y la justicia moral antes de ser conceptos jurídicos se revelan como figuras mitológicas

\footnotetext{
1 Escuela Bíblica de Jerusalén: Biblia de Jerusalén, Bilbao, Desclée de Brouwer, 1988, p. 386.
} 
relacionadas entre sí: Thémis y Díkē. Thémis, hija de Gea y Urano, representa el orden divino del cosmos frente a Díkē que indica el destino que inicialmente los dioses y más tarde las leyes establecen para los hombres. Del matrimonio entre Zeus y Thémis nacen, pues, dos grupos de hijas: las Horas y las Moiras. Las primeras, Díke (la Justicia), Eunomía (el Orden conforme a la Justicia) e Irene (la Paz) protegen las cosechas de los hombres mortales y no se oponen a su madre sino que complementan y amplían el ámbito de aplicación de su justicia al expresar el buen orden de los dos mundos divino y humano. Las Moiras son tres: Láquesis (la que Asigna la porción de lana o de Destino), Cloto (la Hilandera del Destino) y Átropos (la Tejedora del Destino). ${ }^{2}$ En Homero aparecen asociadas a la muerte como destino último del hombre (frente a la inmortalidad de los dioses), dispensan felicidad o desgracia, y tienen un valor jurídico en su calidad de diosas vengativas. Como resume muy bien S. Mas Torres: "en tanto que representan la muerte, la felicidad, la desgracia y la venganza, las Moiras se complementan con sus hermanas: si se respeta la justicia de Zeus surge la paz y la seguridad (Horas) y si, por el contrario, se la quebranta es inevitable la venganza de Crónida, la muerte y la desgracia (Moiras)". ${ }^{3}$ En el mundo arcaico griego la justicia de los seres humanos se enlaza, pues, con un deber no autónomo, sino anclado cósmico-teológicamente en las narraciones míticas de Prometeo y de las Edades donde aparece, por primera vez, la contraposición entre díke e hýbris o la violación del límite, la desmesura. ${ }^{4}$ Allí, el modelo de todo crimen consiste en rebasar la porción de destino asignada a cada uno por Láquesis, en traspasar sus límites, y en tratar de apropiarse de algo más de la parte justamente donada (plenoexia); y es por eso que a Díkē, al personificar la función igualitaria de la justicia, le corresponde por el símbolo de la espada «la división de las cosas en partes iguales»..$^{5}$ Con Hesíodo, en efecto, el principio del respecto del límite adquiere una connotación jurídica al representar el contenido del nómos, es decir la medida universal impuesta por Zeus que se contrapone a la hýbris: la violación del límite. Límite, pues, es lo que circunscribe las posibilidades humanas: hýbris es la voluntad de trascender la condición humana; límite es el confine que marca la inconmensurable distancia entre hombres y dioses: hýbris es la soberbia contra los dioses; límite es el cumplimiento del mandato de los dioses: hýbris es el desconocimiento de aquél mandato; límite es el confine que marca el estatus social: hýbris es la transgresión de los límites impuestos por la propia condición socio-económica. La riqueza, por ejemplo, no se ha de arrebatar al próximo mediante el hurto o el engaño; es mucho mejor y más permanente cuando es dono de Zeus y cuando adviene

\footnotetext{
2 Onians, R.B.: Le origini del pensiero europeo, Milano, Adelphi, 1998, pp. 499-502.

3 Mas Torres, S.: Ethos y Pólis. Una historia de la filosofía práctica en la Grecia clásica, Madrid, Istmo, 2003, pp. 52-58.

4 Jellamo, A.: Il cammino di Dike. L'idea della giustizia da Omero a Eschilo, Roma, Donzelli, 2005.

5 Del Vecchio, G.: La giustizia, Roma, Studium, 1946.
} 
en su estación apropiada en el ciclo del año. Eurípides, en efecto, basa el gobierno de la justicia o igualdad entre los hombres precisamente en la igualdad que observa el curso de la naturaleza, y concluye que la igualdad es lo naturalmente legal para los hombres. La máxima moral de vivir conforme a la naturaleza queda reflejada en Las Fenicias donde Yocasta disputa así con Eteocles: "La igualdad, en efecto, trae estabilidad a los hombres; en cambio, lo menor siempre acaba erigiéndose en enemigo de lo mayor y da comienzo a una época de hostilidades. La igualdad, asimismo, dispuso entre los hombres un sistema ordenado para las medidas y unidades de peso y definió el sistema de numeración. El ojo oscuro de la noche y la luz del sol van avanzando paso a paso, cada uno en igualdad de condiciones a lo largo de su ciclo anual, y ninguno de los dos, al verse vencido, mira con envidia al otro. En consecuencia, el sol y la luna son esclavos de las medidas. ¿Entonces, tú no vas a contentarte con poseer tu parte proporcional de la herencia y compartirla con éste? [Polinices] Y entonces, pues, ¿donde queda la justicia?"6 Será en entorno al VI siglo, pues, cuando la Escuela Pitagórica enunciará el más preciso y estricto significado del concepto de justicia moral como «medida» en las relaciones humanas, es decir igualdad de derechos y deberes políticos entre todos los ciudadanos. Su conocimiento de la geometría había enseñado, tanto a los hombres como a los dioses, el gran poder de la proporción; por el contrario, los ignorantes confían en conseguir apropiarse de algo más de lo que según justicia es suyo. Para Pitágoras la justicia humana es esencialmente igualdad; de ahí la exigencia del resarcimiento que se lleva a cabo a través de la pena, donde se devuelve el mal por el mal. Y Solón presenta su obra legislativa como una mediación entre las aspiraciones de igualdad social y política de los pobres y la voluntad de los ricos de defender sus privilegios; su intención es la de realizar un buen gobierno o una buena constitución capaz de frenar precisamente la codicia y la arrogancia de los ciudadanos y enderezar los juicios torcidos para que cada uno tenga derechos y deberes de acuerdo con su función y capacidad. La antitesis entre hýbris y dike se convierte, pues en la antitesis entre la opresión política y la igualdad de derechos y deberes políticos garantizada por la ley o isonomía. ${ }^{7}$ También Platón sostiene y desarrolla ampliamente la idea general de justicia como igualdad proporcional entre las diferentes clases sociales para el bien de toda la ciudad. A lo largo de sus obras, además, Platón pone en evidencia la importantísima diferencia entre la igualdad aritmética y la igualdad geométrica de la que hablaremos en la secunda parte del artículo. ${ }^{8}$ Aristóteles, de acuerdo con Platón, plantea una teoría de la justicia en la cual caben tanto el concepto más

\footnotetext{
6 Eurípides, Tragedias. III. Las Fenicias, Madrid, Cátedra, 2005, pp. 119-120.

7 Harris, E. M.: Democracy and the Rule of Law in a Classical Athens, New York, Cambridge University, 2006.

8 Platón: Las Leyes, Madrid, Centro de Estudios Políticos y Constitucionales, 1999, pp. 205-206.

"Hay, en efecto, un antiguo dicho, el de que la igualdad produce amistad, que es verdadero y se ha formulado con mucha exactitud y sensatez; pero qué clase de igualdad será la que actúa de ese modo,
} 
general de virtud política como el concepto más restringido y específico de igualdad, en las dos acepciones homónimas pero casi opuestas planteadas por Platón: la igualdad aritmética y la igualdad geométrica o proporcional. En el V Libro de la Ética a Nicómaco, en efecto, Aristóteles establece una relación, también etimológica, entre la justicia, la ley y la igualdad - de tal manera que se dirá que una ley es políticamente justa cuando establezca una determinada forma de igualdad entre los ciudadanos- y distingue entre dos especies de justicia conforme al tipo de igualdad que se quiera llevar a cabo: por un lado está la justicia distributiva y por el otro la justicia correctiva, a su vez dividida en conmutativa y reparadora. Aristóteles, en efecto, reconoce dos significados a la palabra justicia: 1) «lo justo es lo legal» o la justicia política (el todo de la justicia); 2) «lo justo es lo igual» o la justicia distributiva y correctiva (las partes de la justicia); por consiguiente lo injusto será lo ilegal y lo desigual. Ambos significados de la justicia definen, además, respectivamente a la justicia material y a la justicia formal: la justicia política o material se identifica con la Ley o Constitución de cada República, es decir, con los regímenes políticos que ponen en marcha los ciudadanos con el fin de promover el bien común; mientras que la justicia distributiva, o formal, se identifica con el concepto de igualdad y se refiere a la distribución de los bienes básicos entre ciudadanos: los derechos políticos (los honores) y los derechos económicos (las riquezas). La justicia, entendida en este sentido, consistirá por lo tanto en la justa medida con la que se dividen los derechos y los deberes, los bienes y los males, los beneficios y los costes, las ventajas y desventajas, las ganancias y las pérdidas entre los ciudadanos. Así que la justicia distributiva es un término medio entre un más y un menos, es decir entre los dos extremos de la injusticia. El hombre que es injusto en este sentido es el hombre que toma para sí más bienes y menos males de los que le corresponde; la hýbris, según el Estagirita, es un vicio particular que debe ser distinguido de los otros «siendo su móvil el placer que resulta de la ganancia», es decir del lucro, y es a este vicio al que más en particular se aplica el nombre de «injusticia». La jus-

he aqui algo que, por no estar enteramente claro, nos perturba en grado sumo. Pues habiendo dos clases de igualdad, homónimas, es cierto, pero de hecho casi opuestas entre sí por muchos modos, la una de ellas, la igualdad determinada por la medida, el peso y el número, no hay ciudad ni legislador que no sea capaz de aplicarla con respeto a los honores asignándola por sorteo en lo que toca a los repartos; mientras que la más auténtica y más excelente igualdad, eso ya no es fácil para cualquiera el dilucidarlo. Porque ésta nace del juicio de Zeus, y es siempre pequeña la medida en que presta su ayuda a los hombres; pero eso sí, sea cualquiera el grado en que colabore con las ciudades o los particulares, lo que produce es todo bueno. Otorga, en efecto, más al que es mayor y menos al que es menor, dando a cada uno lo adecuado a su naturaleza; y también en cuanto a distinciones, concediéndoselas siempre mayores a los más excelentes en punto a virtud y al contrario a los que son de manera distinta por lo que toca a virtud y educación, distribuye proporcionalmente lo conveniente por cada cual. Ahora bien, para nosotros, según creo, la política no es nunca más esto mismo, lo justo, a lo cual - ;OH Clinias!, debemos ahora tender, teniendo la vista fija en este tipo de igualdad, en la fundación de la ciudad que ahora está naciendo." 
ticia distributiva se diferencia, además, de la justicia correctiva, la cual regula normativamente las relaciones privadas entre los ciudadanos castigando, consecuentemente, a los que incumplan las leyes. Ésta última a su vez tiene dos partes: la primera disciplina las relaciones y los intercambios que los ciudadanos establecen voluntariamente, como los contratos de compra, de venta, el préstamo, la fianza, el usufructo, el alquiler, etc. (justicia conmutativa); y la otra parte sanciona aquellas relaciones que los ciudadanos establecen o padecen sin querer y que pueden ser fraudulentas o violentas, como el robo, la estafa, el asesinato, el falso testimonio, la difamación, el insulto, etc. (justicia reparadora). Aristóteles trata de probar que, en cada una de las dos partes de la justicia, lo mejor consiste en el establecimiento de una cierta proporción de igualdad, bien geométrica bien aritmética, según se hable de la justicia distributiva o de la justicia correctiva. ${ }^{9}$

\section{El origen etimológico de la palabra dikē y la doctrina cosmológica de las ideas de Platón: la analogía de la línea del horizonte.}

Interpretando el apotegma atribuido a Pitágoras (Yámblico, Vit. Pyth., IX, 46) -según el cual «Thémis en el reino de Zeus y Díkē en el mundo inferior, detentan el mismo lugar y rango que pertenece a Nómos en las ciudades de los hombres; de manera que aquel que no cumple el deber que se le ha asignado puede considerarse como violador del orden de todo el universo»-, Cornford10 afirma que antiguamente la estructura del cosmos era un orden moral o sagrado porque se sostenía que la estructura y comportamiento del mundo formaban un todo continuo con la estructura de la sociedad humana (o eran una mera extensión suya). Thémis, Díkē y Nómos representan así las tres formas de hacer justicia y de dictar la ley: dos de ellas, como hemos visto, son de origen divina; la tercera -nómos - se divinizará en la misma medida en que la convivencia se hace más política. En efecto, pese a lo que se pueda pensar a primera vista del prestigio que goza al menos desde Heráclito en adelante, la palabra nómos no es una palabra antigua -no aparece en Homero- y su uso político es menos antiguo todavía. Su expansión es un indicador de las profundas modificaciones que se han producido en el pensamiento y en las instituciones de Atenas: un indicador de la transformación democrática de la pólis. La poesía de Homero refleja la época de la thémis, de un «derecho divino de los reyes» -por utilizar una expresión moderna- que mucho tiene que ver con la organización prepolítica en grupos familiares. En la ciudad homérica, pues, todavía no se ha impuesto la ley: se trata, más bien, de un sistema de relaciones feudales en el que el rey

\footnotetext{
9 Véase también Salamone, M.A.: La Ética y la Política de Aristóteles: una cuestión de proporciones áureas, Milán, Lampi di Stampa, 2007.

10 Cornford, F. M.: De la religión a la filosofía, Barcelona, Ariel, 1985.
} 
(basileús) o señor detenta el poder supremo; y a él le corresponden las disposiciones, órdenes y mandatos que hacen justicia (thémistes). Como afirma muy bien Benveniste, el término thémis hace referencia a una organización «gentilicia» familiar en la que el señor impone deberes y concede derechos: "En la epopeya se entiende por thémis la regla o prescripción divina que fija los derechos y los deberes de cada cual bajo la autoridad del jefe del génos tanto en la vida cotidiana, en el interior de la casa como en circunstancias excepcionales: alianza, matrimonio, combate. La thémis es patrimonio del rey, que es de origen celeste, y el plural thémistes indica el conjunto de estas prescripciones, código inspirado por los dioses, leyes no escritas, colección de dichos, fallos, sentenciados por los oráculos, que fijan en la conciencia del juez, el patriarca, la conducta que debe mantenerse siempre que el orden del génos esté en juego". ${ }^{11}$ Se trata, a fin de cuentas, de la casa y de su ley, de una oiko-nomía (que, sin embargo, todavía no conoce el valor legal de la palabra nómos) en la que la decisión del cabeza de familia está protegida por la procedencia divina de su poder y autoridad. En efecto, si hay un punto de acuerdo entre todos los investigadores sobre el significado de la palabra es éste: la thémis es de origen divino, forma parte del equipamiento real y alude principalmente al ámbito familiar, junto a díké a la que se invoca en cuestiones interfamiliares. ${ }^{12}$ Bonner ${ }^{13}$ comenta, al respecto, que en el lenguaje jurídico homérico dikē comparte con thémis la idea general de justicia, aunque dikē representa estrictamente la aplicación de la thémis por parte del rey que puede equivocarse fácilmente a la hora de aplicar la justicia dado que existen una multiplicidad de thémistes. De hecho, según MacDowell, ${ }^{14}$ en la sociedad arcaica el rey no hace otra cosa que aplicar su propio criterio para resolver las controversias. Por supuesto que normalmente se dejaría guiar por los hábitos o las costumbres vigentes sobre lo correcto y lo incorrecto, o por las decisiones tomadas anteriormente en casos similares, o por las opiniones de otras personas presentes en la asamblea, incluida la multitud de espectadores. A pesar de eso, un rey justo a menudo encontraría su procedimiento judicial inadecuado, mientras que un rey egoísta tendría a su alcance la posibilidad de resolver un litigio de forma favorable para sí mismo. La función más importante de la ley será, por lo tanto, la de reducir precisamente esas dudas y arbitrariedades. “¿Por qué se empezaron a escribir las leyes? Cabe pensar: por presión popular, para que las

11 Benveniste É.: Vocabulario de las instituciones indoeuropeas, Madrid, Taurus, 1983, pp. 297-300. 12 De la amplia bibliografía destaco: Hirzel R.: Temis, Dike und Verwandtes, Hildesheim, Georg Olm, 1968; Harrison, J.: Themis, Cambridge, University Press, 1912; Harrison, J.: Prolegomena to Study of Greek Religion, Cambridge, University Press, 1903; Oncina Coves, F.: Teorías y prácticas de la historia conceptual, Madrid, Consejo Superior de las Investigaciones Científicas, 2009.

13 Bonner, R. J.: The Administration of Justice from Homer to Aristotle, New York, Greenwood Press, $1968, \mathrm{p} 10$.

14 MacDowell, D.M.: The Law in Classical Athens, New York, Cornell University Press, 1978, pp. $42-52$. 
normas consuetudinarias se estabilizaran y no fueran susceptibles de interpretación arbitraria por parte de las aristocracias dominantes. Pero cabe sostener la tesis contraria, a saber, que los círculos aristocráticos estabilizaron y escribieron leyes antes de que las presiones populares acabaran con los privilegios implícitos $y$ explícitos recogidos en las leyes tradicionales no escritas". ${ }^{15}$ Sea como fuere, durante la época clásica todas las comunidades civilizadas ponen las leyes por escrito (en Atenas, como se sabe, las primeras leyes fueron escritas por Dracón): la ley se convierte en un acto público de la pólis, conocido por todos, puesto que garantiza los derechos y deberes políticos de los miembros de la comunidad, independientemente de su pertenencia a esta o aquella familia aristocrática. La justicia pasa a ser competencia exclusiva de la polis, los delitos pierden el carácter sagrado y se afirma el principio y el valor del nómos, es decir de la ley escrita por el buen legislador, frente a los juicios arbitrarios de los reyes. ${ }^{16}$ Paralelamente, se precisa y profundiza también el vocabulario que se desprende parcialmente del significado teológico. Según Aristóteles, en efecto, los términos dikastếs, «giudice» y dikaion, «justo, equitativo, legitimo, conforme al derecho» proceden etimológicamente de la raíz dikē, «habito, costumbre, regla, sentencia, juicio, procedimiento judicial», que a su vez deriva del término díksē, «en dos partes, bisección» y del adverbio diksa «dividido en dos partes iguales». He aquí el famoso texto en que Aristóteles establece la sinonimia entre lo justo y lo igual: "Cuando el todo se divide entre dos, se dice que cada uno tiene lo suyo cuando han recibido partes iguales, y lo igual es un término medio entre lo mayor y lo menor según la proporción aritmética. Esta es también la razón de que se llame justo (dikaios), porque es una división en dos partes iguales (diksa), como si se dijera díksaion y el juez diksastếs."17 Lo justo es lo igual, repite con gran insistencia el filósofo griego, y tal es, pues, la noción primera y fundamental de la justicia y del derecho en Aristóteles quien, en su especial fraseología matemática, habla de la identificación de la justicia con la idea de igualdad aritmética o geométrica; y esta igualdad la vierte por la idea de una justa proporción, es decir por la idea de un término medio entre dos extremos, lo cual constituye la regla o medida objetiva que tiene que aplicarse a las normas justas o legales. El adverbio diksa, además, procede de la raíz griega dís, «dividir en dos partes, dicotómico», que a su vez deriva de la raíz sánscrita *diś-(dik) cuyo significado además de referirse genéricamente al verbo «mostrar»- de donde la metáfora de

\footnotetext{
15 Mas Torres, S.: op. cit., p. 71.

16 Kahn subraya, al respecto, que tanto Solón como Heráclito ponen énfasis políticamente en la función igualitaria de la ley como término medio entre las dos clases sociales desiguales: la de los pobres y de los ricos. Véase Kahn, Ch. H.: The Art and Thought of Heraclitus, Cambridge, Cambridge University Press, 1979, pp. 179-181.

${ }^{17}$ Aristóteles: Ética a Nicómaco, Madrid, Centro de Estudios Políticos y Constitucionales, 2002, p. 76.
} 
mostrar el camino recto en sentido físico y moral o la «línea recta», 18 - indica especificadamente el concepto espacial de «línea del horizonte», es decir de línea divisoria que marca un confine o límite entre el cielo y la tierra. En efecto, en el diccionario de Monier, todos los términos que proceden de la raíz * diśs- $(d i k)^{19}$, como por ejemplo: dikanyā, «la cuarta parte del cielo»; dicakra, «la cuarta parte de la brújula, el compás, el horizonte»; dikpatha, «la vía del horizonte» y diktata, «la línea del horizonte», indican la línea del horizonte o el espacio circular de la superficie del globo, encerrado por la línea del horizonte. De hecho, tanto la descripción astronómica del cosmos dividido en cuatro partes - «la cuarta parte del cielo»-, como la descripción geométrica de los cuatro puntos cardinales - «la cuarta parte de la brújula»-, indican el horizonte astronómico o racional que se define como una línea horizontal que pasa por el centro de la tierra y es perpendicular a la línea cenit-nadir o línea vertical del hemisferio celeste. En términos generales, el horizonte astronómico o racional es, por consiguiente, la línea que limita la superficie terrestre a que alcanza la vista del observador y divide aparentemente el cosmos en dos partes iguales: la tierra y el cielo. El significado más específico de lo justo concreto o díkaios sería, por lo tanto, bipertitum o dicotómico, lo dividido en dos partes iguales. Sin embargo, la etimología tradicional hace derivar díkē de la raíz * deík del verbo deiknymi «mostrar, indicar», de donde dike viene a significar «indicación, dirección, camino, costumbre». ${ }^{20}$ Esta derivación ha sido rechazada abiertamente por Hirzel21 con el argumento de que el significado de «fallo o sentencia del juez» es predominante en la Ilíada, mientras que el significado de «camino o costumbre» aparece sólo en la Odisea y, por lo tanto, debe ser un desarrollo posterior; el autor, en efecto, hace derivar aristotélicamente el término dike del verbo díkein que quiere decir «pronunciar un juez o un tribunal una sentencia». Un nuevo e interesante enfoque etimológico ha sido sugerido por Palmer22 que reconoce dos significados fundamentales de la palabra díke que se han desarrollado separadamente a partir de la raíz griega *deik: (a) indicación, característica, modo de ser propio y (b) confine

\footnotetext{
18 Rendich, F.: Dizionario etimologico comparato delle lingue classiche indoeuropee, Roma, Palombi, 2010, pp. 160-161.

19 Monier, W. M.: A Sanskrit English Dictionary Etymologically And Philologically Arranged With Special Reference To Cognate Indo-European Languages, Oxford, Clarendon Press, 1964, pp. 479480.

20 Benveniste, É., op. cit., p. 301. Sobre esta derivación quiero destacar las dudas de Benveniste: "Se trata de una raíz deík que da, respectivamente, dís, en sánscrito, dis-en iranio; dico en latín; deíknymi, en griego. Pero estas formas, tan exactamente correspondientes, no concuerdan en su sentido, puesto que el griego deíknymi significa 'mostrar'y el latín dico 'decir'. Por tanto, mediante un trabajo de análisis, habrá que llegar a despejar el sentido que explique que dikè tiene el sentido de justicia".

21 Hirzel, R.: op. cit.

22 Palmer, L. R.: The Indo-European Origins of Greek Justice, en "Transactions of the American Philological Society", Vol. 49, 1950, pp. 149-168 y Gagarin, M.: Dike in the Works and Days, en “Classical Philology", Vol. 68, No 2, 1973, pp. 81-94.
} 
o límite espacio-temporal, línea divisoria. Según el autor, de (a) se derivaron los significados de "característico", "tradicional", "comportamiento adecuado"; y de (b) procedieron los significados asociados a la acción de expresar el juicio que decide a favor de una de las dos partes contendientes, lo que se representa metafóricamente trazando una línea divisoria entre ellas. En efecto, según Palmer, originariamente el término díke se utilizó especificadamente para demarcar los límites que separan dos terrenos, dos territorios o dos países, lo cual se lograba trazando una línea divisoria entre ellos. A partir de allí, el uso del término se extendió hasta incluir el significado jurídico de «pronunciar o dictar una sentencia» que resuelve un litigio entre dos partes. De manera que, según Palmer, el significado principal del término justicia radica en la «idea de límite» o «línea de demarcación territorial» y tiene, además, un valor normativo. Pero: ¿qué es lo que señala el concepto espacial de justicia como línea divisoria? ¿Es posible que ese concepto haga referencia etimológicamente a la línea del horizonte? Y si eso es así, por lo que se refiere al aspecto normativo del término: lo que indica el horizonte astronómico ¿no podría coincidir precisamente con el concepto de igualdad o de división del cosmos en dos partes iguales: el cielo y la tierra? Palmer parece confirmar esta hipótesis cuando afirma que desde el punto de vista etimológico el núcleo central de la idea de justicia gira entorno al concepto cosmológico de división/distribución del universo, y explica además que esa idea procede de la cosmogonía griega de la que habla Alcmán, el poeta más antiguo de la lírica coral griega, en su Partenio del Louvre. En esta obra, pues, Alcmán habla del mito cosmológico de Aisa (la parte, el destino asignado) y Poros (distribución, límite o línea divisoria): los dos principios o dioses primigenios que llevaron a cabo el acto primordial de justicia distributiva, es decir la primera gran división del universo en dos partes -el Cielo y la Tierra- gracias a la cual se alcanzó el orden natural del cosmos. Desde el punto de vista moral y político el mito se condensa en la máxima «que ningún hombre vuele hasta el cielo ni intente casarse con Afrodita», y expresa una característica importante de la moral arcaica griega: la necesidad de no ir más allá de los propios límites, de no caer en el exceso y de cumplir adecuadamente con el papel o la parte asignada por el destino. ${ }^{23} \mathrm{La}$ moralidad griega está gobernada, en efecto, por el precepto «conócete a ti mismo y no vayas demasiado lejos»: ir demasiado lejos constituye plenoexia, o sea «tener mayor porción del destino que la justamente asignada», hýbris, o «incurrir en desmesura», o bien transgresión, invasión de la esfera que el próximo tiene derecho a ocupar íntegramente ${ }^{24}$. Ya Cornford había señalado que la filosofía griega hereda de la religión

\footnotetext{
${ }^{23}$ AA.VV.: The Cambridge History of Classical Literature, Cambridge University, Easterling and B. M. Knox, 1985.

${ }^{24}$ El mítico viaje que Alejandro Magno emprendió sobre dos grifos para alcanzar el cielo o los confines del mundo representa bien el sentido de la palabra plenoexia o híbris. Véase Pseudo-Calístenes: Vida y hazañas de Alejandro de Macedonia, Madrid, Gredos 1988.
} 
la concepción rectora de un determinado orden de la naturaleza, alternativamente considerado como reino del destino, de la justicia o de la ley; y que el carácter y origen de tal orden es, a la vez, un dominio moral, un principado de la justicia25. Para la representación religiosa de los griegos, al igual que para su primigenia filosofía, la verdad más importante respecto al mundo era que éste se hallaba dividido según un esquema general de competencias asignadas o de esferas de poder. Las cuatro formas elementales de la materia -la tierra, el aire, el agua y el fuego-, según la mayoría de los primeros filósofos, pasaron a poseer sus regiones fijas cuando el movimiento eterno estableció los primeros límites dentro de la physis primordial e indiferenciada (dentro del ilimitado uno o lo ápeiron), a la que Anaximandro llamó lo limitado o peras: en primer lugar está la gran masa de la tierra; por encima, o acaso por debajo, están las aguas; a continuación, el espacio llenado por el viento, la niebla y las nubes; y, más allá de todo esto, el fuego abrasador del cielo, el éter. Empédocles, además, convirtió esos cuatro elementos en las raíces de todas las cosas planteando, además, su igualdad en términos muy claros dado que los elementos no están solamente separados en regiones distintas, sino que se hallan agrupados en parejas de contrarios (fuego y aire, agua y tierra). ${ }^{26}$ Se trata de una cosmología en la cual están unidos la justicia, el derecho y la igualdad, y este orden de la naturaleza es moral en el sentido de que la reciproca agresión de los elementos en su lucha perpetua, la violación de sus límites y por ende de su igualdad, representa una injusticia, una transgresión moral. De modo similar, continúa el autor, los tres dioses homéricos que adquirieron sus dominios del cosmos en virtud de la asignación de Cronos, eran iguales en rango y en posesiones. En el Canto XV de la Ilíada, en efecto, los dioses -que nacieron de los cuatro elementos-, al enfrentarse con el problema de la distribución de la tierra, se repartieron las riquezas y distribuyeron los honores a través de un primer acto de justicia distributiva protagonizado por Cronos quien dividió el cosmos en partes iguales entre los hijos Zeus, Poseidón y Hades: "Pues tres hermanos somos, nacidos de Cronos y Rea: Zeus y yo (Poseidón), y Hades es el tercero, el señor de los muertos. Y todas las cosas fueron divididas en tres regiones y cada uno tomó la parte (o privilegio, o rango) que le correspondía. Al repartírnoslo, me tocó a mí el proceloso piélago, para que en él habitara para siempre; y Hades obtuvo la nebulosa tiniebla y Zeus el ancho cielo entre el éter y las nubes, pero la tierra y el elevado Olimpo son comunes a los tres. Por lo tanto, jamás obraré conforme al propósito de Zeus; no, y por más que su poder sea grande, que viva tranquilo en esa tercera parte que es suya." 27 En este

25 Cornford, F.M.: op.cit., p. 17.

26 Aristóteles, Acerca de la Generación y Corrupción, Madrid, Gredos, 1987.

27 Cornford, F.M.: op. cit., p. 29. La traducción de Homero es de Cornford. En la Teogonía de Hesíodo también hallaremos una división del cosmos en tres partes (moirai) exactamente igual que la vista en Homero. Y Sealey, de acuerdo con las interpretaciones de Palmer y Cornford, pone el acento sobre la gran preocupación de Homero por la justicia distributiva, añadiendo que la cuestión de la distribución 
pasaje justicia sencillamente significa parte o lote asignado, y está fuera de discusión que de ese significado básico se deriva el de destino: "Cada dios posee su parte o dominio asignado, esto es, cierto espacio de la naturaleza o campo de actividad. A la vez ése puede considerarse como su rango, que le confiere determinada posición, en un sistema social y en algunas ocasiones se le llama su privilegio. Dentro de su campo tal supremacía no puede discutirse; pero quien la ostenta no debe transgredir las fronteras y sentirá encono ante cualquiera usurpación". 28 De esta manera, en Homero, y en general en el pensamiento jónico, nos encontramos con una creencia profunda en la justicia o destino en cuanto ordenación que limita todos los poderes individuales, divinos y humanos; y vemos además que tal ordenación se parece más a un decreto de obligación moral que a una delimitación de mera imposibilidad física. De acuerdo con Cornford, además, esta concepción original que representa la justicia como una divina división del cosmos en dos partes iguales, o dasmós cósmico, resulta ser tanto espacial (se divide el cielo de la tierra) como temporal (se divide el día de la noche), y tiene sus antecedentes en la cosmogonía antigua: “Antes de la cosmología, existieron la cosmogonía y la teogonía. Se concebía el devenir como un nacimiento, y todo nacimiento resulta de un matrimonio. El maridaje primordial es, en las cosmogonías primitivas, la unión del Cielo y la Tierra, lo que la religión antropomórfica de los tiempos históricos representó como el matrimonio ritual de Zeus, o Júpiter, y de su acompañante femenina. Pero el Cielo y la Tierra no pueden unirse en fértil matrimonio hasta que no se les haya separado de su original unidad de formas. Asi las cosmogonías no empiezan con el himeneo, sino con la separación del Cielo y la Tierra."29 Según los antiguos, pues, al principio Cielo y Tierra eran uno, es decir el mundo comenzó como una masa indiferenciada, sin fronteras o lindes internas, esto es, un ilimitado uno. Esta masa se dividió luego en dos partes, las cuales eran opuestas o contrarias: la Tierra (hembra) y el Cielo (macho). Por último, Eros unió la Tierra al Cielo: los contrarios se combinaron y dieron el ser a la existencia individual de la primera generación de los dioses: los Titanes, las Titánides, los Cíclopes y los Hecatónquiros. ${ }^{30}$ De manera

de los bienes surgió con regularidad, por ejemplo, en las comidas comunales (Sealey, R.: The Justice of the Greek, Michigan, University of Michigan Press, 1994, pp. 138-142).

28 Cornford, F.M.: op. cit., p. 30.

29 Cornford, F.M.: op. cit., p. 85-86.

30 En la Teogonía de Hesíodo (124 y ss.) Urano es engendrado por Gea que lo alumbra con sus mismas proporciones, lo que demuestra la igualdad geométrica entre los dos. Este acto de alumbramiento asexuado ha sido concebido, además, como una versión cosmogónica del principio cosmológico de la separación del cielo y la tierra a partir de una masa indiferenciada, cuya versión poética se representa a través del mito de la castración de Urano por parte de Cronos. Tras su castración, en efecto, Urano no volvió a cubrir Gea por la noche, sino que ocupó su lugar en el cosmos. De la sangre de Urano nacieron las Erinias, los Gigantes y las Melias (los dioses que representan la fuerza de la discordia); mientras que de la blanca espuma de Cronos nació Afrodita y, detrás de ella, Hímero y Eros (los dioses que representan la fuerza del amor). 
que si estamos en lo cierto al pensar que el último significado o arquetipo de la justicia es la de división del universo en diferentes porciones, entonces nos resultará clarísimo que tal división, en cuanto se convierta en labor de un dios personal, ya puede concebirse como una nomothesia, un establecimiento o fijación de nomoi; y que este proceso es sencillamente una redistribución, para dioses y hombres, de sus dominios, privilegios y honores. En efecto, al final de la guerra divina de sucesión, cuando Zeus asumió su sede en el trono de Cronos inaugurando la dinastía olímpica, de inmediato distribuyó entre las divinidades sus varios privilegios y ordenó jerárquicamente su reino, confirmando parcialmente el sistema constitucional de Cronos y, a la vez, ampliándolo mediante otras particiones. ${ }^{31}$ Afrodita, por ejemplo, se ocupará del amor y de la seducción; Hera del matrimonio legítimo, Atena de la sabiduría y de la estrategia de la guerra, mientras que Thémis se ocupará de la justicia divina. Por lo que se refiere a los anthropoi, además, Zeus quiso poner a los hombres en su sitio trazando una «línea divisoria» que separase definitivamente el destino inmortal de los dioses de la condición humana de los andrei, tal como se narra en el mito de Prometeo que termina con la donación por parte de los dioses de un kalon kakon o sea un hermoso mal: Pandora, la primera mujer. ${ }^{32}$

También Platón afirma (Critias, 109 b) que los dioses se repartieron entre sí las regiones de toda la tierra, palmo a palmo, no como resultado de una riña, sino amigablemente echando a suertes los lotes de la justicia y gobernando no mediante la violencia, sino persuadiéndonos con la razón. Además, según mi opinión en la República (libros VI y VII) Platón utiliza la alegoría de la «línea del horizonte» para explicar su doctrina cosmológica de las Ideas, es decir el proceso epistémico que desde la oscuridad de la dóxa propia del mundo sensible, avanza progresivamente hacia la luz de la epistéme, propia del mundo inteligible, gracias al utilizo de las ciencias matemáticas $\mathrm{y}$, sobre todo, de la dialéctica filosófica. De este modo, las cuestiones políticas y morales se entretejan con las de orden cosmológico y metafísico, como queda prescrito, desde el comienzo mismo del Timeo, por la referencia al diálogo que transcurre durante la víspera literaria, la República. El punto de par-

\footnotetext{
31 Cornford hace notar que para designar tal acto, Esquilo (Prometeo encadenado, 244) emplea el vocablo némein, distribuir, es decir precisamente la palabra de la que se deriva nómos, ley. Lo que Zeus estaba haciendo era, ni más ni menos, sentar oficio de legislador. El autor subraya, en efecto, que tras el conocido sentido de "costumbre", "uso", "ley" como traducción de nómos se ven rastros de un significado espacial más antiguo: la noción de un territorio o región dentro del que pueden ejercerse legalmente ciertos derechos definidos, los que los romanos llamaron provincia. Para la intelección del término heleno es menester comprender que nómos no surgiere uniformidad de secuencia temporal sino ejercicio de un poder dentro de unas líneas espaciales o departamentales. Tenemos que considerar a la ley como una distribución o sistema de regiones dentro del cual están repartidas y coordinadas todas las actividades de la comunidad.

32 Véase Vernant, J.P. : Pandora, la première femme, Paris, Bayard, 2006 y Los orígenes del pensamiento griego, Barcelona, Paidós, 2011.
} 
tida de la cosmología platónica es que el universo viviente es aparentemente dicotómico o bipolar puesto que está formado por dos géneros ontológicos diferentes: uno visible y tangible, «el ser divisible que deviene en los cuerpos», es decir el cuerpo material del cosmos que cambia incesantemente (las Apariencias); y otro invisible e inteligible, «el ser indivisible y que se mantiene siempre del mismo modo», es decir el modelo o forma racional del cosmos (las Ideas/Números); y que la unidad en la multiplicidad del cosmos, es decir el Bien, se adquiere mediante el «más bello de los vínculos», o un término medio geométrico, que ordena y relaciona las dos parte; en efecto, la mediación o conjunción entre los elementos divisibles e indivisibles del cosmos es dada por la inteligencia cósmica o demiurgo que se sirve de un tercer género ontológico intermedio, la khôra o el alma cósmica, ${ }^{33}$ para superar la dicotomía y unificar las dos partes del cosmos: la del ser y la del devenir, la de la unidad y la de la multiplicidad, la de la igualdad y la de la diversidad. Como explica muy bien Gaiser, 34 en el Timeo la estructura del alma cósmica es concebida de forma matemático-geométrica y eso porque Platón sitúa los Entes matemáticos en una posición ontológica intermedia entre las Ideas y las Apariencias. De manera que el dualismo ontológico que funciona de base en muchos otros diálogos platónicos quedaría superado, tanto en la República como en el Timeo, mediante la introducción de un término medio, o receptáculo de toda generación, en el seno del cual estaría emplazado el cosmos. Para explicar la dialéctica de los tres géneros ontológicos -lo que deviene, aquello en lo que deviene, y aquello de cuya semejanza nace lo que deviene- Platón apela (Timeo, $50 \mathrm{~A}-\mathrm{C}$ ) a una suerte de recurso figurativo familiar asociando la khôra a la figura de una madre, el cosmos material a la figura de un hijo que se encuentra alojado en ese receptáculo materno, y las ideas eternas a la figura de un padre progenitor que ha engendrado a este hijo a semejanza suya. Mientras que en la República la figuración de los tres géneros ontológicos quedaría representada, como hemos dicho, a través de la analogía de la «línea del horizonte» cuya función sería precisamente la de dividir la unidad del cosmos en dos partes (el cielo de la tierra), para luego reunificarlo filosóficamente a través de la construcción geométrica del medio proporcional. ${ }^{35}$ Lo que explicaría metafóricamente el proceso epistemológico de la dialéctica filosófica cuyo objetivo final es el de alcanzar la idea del Bien representada por el Sol, o la Ley suprema que determina la estructura ontológica y epistemológica del universo: es decir, la superación de los opuestos o la Igualdad proporcional entre el Todo del Cosmos (Ápeiron/Unidad)

\footnotetext{
33 Brisson, L.: Le Même et l'Autre dans la structure ontologique du "Timée" de Platon : un commentaire systématique du "Timée" de Platon, Sankt Augustin, Academia Verlag, 1998.

34 Gaiser, K.: La dottrina non scritta di Platone. Studi sulla fondazione sistematica e storica delle scienze nella scuola platonica, Milano, Vita e Pensiero, 1994.

35 Hösle, V.: I fondamenti dell'aritmetica e della geometria in Platone, Milano, Vita e Pensiero, 1994, pp.118-121.
} 
y sus partes (Peras/Multiplicidad o Díada Indefinida). Es muy importante destacar en este contexto, y como señala Gaiser, que en este intermedio entre los opuestos hay que reconocer el Bien, designado precisamente como «lo Igual»: " $E l$ «Bien», en cualquier sentido que se le entienda, se determina como lo igual y se conecta con el Principio de la Unidad; el «Mal», por contra, se determina como lo desigual y está ligado, a través del «demasiado» o el «demasiado poco», al Principio de la Multiplicidad y de la Indeterminación". 36 Así que el vínculo analógico entre matemática y ontología nos lleva directamente a las doctrinas no escritas de Platón, puesto que es posible reconducir sistemáticamente todos los aspectos esenciales de la ontología platónica a la relación entre los dos principios matemáticos opuestos. En efecto, a la oposición universal de los principios matemáticos (Uno y Díada indefinida) le corresponde primariamente la oposición ontológica del ser y devenir $\mathrm{y}$, segundariamente, toda la gradación jerárquica que va de las Ideas a las Apariencias, pasando por la oposición axiológica (bien y mal, orden y desorden), la lógico-formal (identidad y diferencia, unidad y multiplicidad), la cosmológica (estabilidad y movimiento) y la epistemológica (ciencia y opinión). De lo que se trata, en definitiva, es interpretar ontológicamente los principios matemáticos puesto que, de acuerdo con el antiguo testimonio del mismo Aristóteles ${ }^{37}$ y con las modernas interpretaciones de la Escuela de Tubinga ${ }^{38}$, Platón establece una correspondencia entre la matemática y la doctrina de las Ideas; es decir entre: a) los números $(1,2,3,4)$; b) las dimensione espaciales (Unidad, Línea, Superficie, Cuerpo; y c) las facultades cognoscitivas (Intelecto, Ciencia, Opinión, Sensación). En la analogía cosmológica de la «línea del horizonte», en efecto, la función mediadora de los Entes matemáticos viene descrita de forma detallada a través de un modelo cuadriarticulado del proceso epistemológico: eikasía (imágenes de las Apariencias) pístis - (Apariencias) - diànoia (Entes matemáticos) - nóesis (Ideas en sí). El esquema sería el siguiente: la «línea del horizonte» divide aparentemente la unidad

\footnotetext{
36 Gaiser, K.: op. cit.; p. 80.

37 Aristóteles, Acerca del alma, Traducción de Tomás Calvo, Madrid, Gredos, 1988, p. 140. "También $y$ de la misma manera construye Platón el alma a partir de los elementos en el Timeo: y es que, a su juicio, lo semejante se conoce con lo semejante y, por otra parte, las cosas se componen de los principios. De manera similar se especifica, a su vez, en el tratado denominado Acerca de la Filosofia, que el animal en sí deriva de la idea de Uno en sí y de la longitud, latitud y profundidad primeras, siendo el proceso análogo para todo lo demás. También, y según otra versión, el intelecto es lo Uno mientras que la ciencia es la Díada: ésta va, en efecto, de un punto de partida único a una única conclusión; el número de la superficie es, a su vez, la opinión y el del sólido es la sensación: se afirma, pues, que los números constituyen las ideas en sí y los principios y, además, que proceden de los elementos y que ciertas cosas se disciernen con el intelecto, otras con la ciencia, otras con la opinión y otras con la sensación. Estos números, por lo demás, son las ideas de las cosas."

38 Véase también, Kramer. H.: Platone e i fondamenti della metafisica. Saggio sulla teoria dei principi e sulle dottrine no scritte di Platone, Milano, Vita e Pensiero, 2001 y Reale, G.: Per una nuova interpretazione di Platone, Milano, Vita e Pensiero, 2003.
} 
del cosmos platónico (Uno) en dos partes (Díada indefinida): una parte sensible vinculada a la Tierra y a la Opinión, es decir a las Apariencias, y una parte inteligible vinculada al Cielo y a la Verdad, es decir a las Ideas/Números. Luego las dos partes del cosmos vuelven a ser cortadas, siguiendo la misma proporción, de manera que los cuatro segmentos representan las cuatro facultades teorético-cognoscitivas que utiliza la mente del hombre para llegar a la verdad: imaginación, creencia, razón discursiva e intelección. Así que el segmento que representa la parte sensible del cosmos (la tierra) al referirse al conocimiento que se alcanza a través de los sentidos, es decir a la opinión, estaría cortado en dos partes: a) la eikasía o la visión de las imágenes de las Apariencias y b) la pistis o la visión de las Apariencias; mientras que el segmento que representa la parte inteligible del cosmos (el cielo) al referirse al conocimiento que se alcanza a través de las ciencias matemáticas y filosóficas, es decir a la verdad, estaría cortado en otras dos partes: c) la diànoia o la visión de los Entes matemáticos, y d) la nóesis o la visión de las Ideas en sí. Ahora bien, de acuerdo con Gaiser, Hösle y Balashov entre otros, 39 se deduce que la línea (del horizonte) estaría cortada en media y extrema razón de manera que la imaginación es a la creencia como la razón discursiva es a la intelección, y la opinión a la verdad. Es decir, Platón establece una relación de igualdad entre el todo del cosmos y sus partes -entre el modelo inteligible del universo (el mundo de las Ideas/cielo) y su copia visible (el mundo sensible/tierra) - a través de un medio geométrico -la sección áurea- que pone a los dos en conexión. Lo que Platón quiere demostrar es que la división en dos partes de la totalidad del cosmos es análoga a la división de cada una de sus partes; o sea que entre el mundo del ser y el mundo del devenir, entre las Ideas y los Entes matemáticos y entre las Apariencias y sus Imágenes tiene que valer el mismo lógos: se trata, en definitiva, de establecer matemáticamente una relación de igualdad entre el original y su copia. Por lo tanto, la hipótesis de un rol cosmológico de la sección áurea, o división continua, radica en el convencimiento de que también en la cosmología platónica como en las demás antiguas el universo nace de una unión o maridaje cósmico: el dásmos platónico, en efecto, no separa definitivamente el universo en dos regiones opuestas (el paterno cielo y la materna tierra) sino que, después de la partición, unifica las dos partes a través de un medio geométrico-espacial o alma cósmica (papel desempeñado antiguamente por Eros) lo que da origen al devenir de todas las cosas. Y es significativo, al respecto, que Platón (Timeo, 50 b) compare el medio geométrico, o la khôra, con el oro que el orfebre-demiurgo utiliza para moldear y ordenar toda clase de figuras geométricas a la hora de fabricar el alma cósmica, y que por eso afirme que la khôra pertenece a una especie ontológica invisible y amorfa que recibe siempre todo (como un

\footnotetext{
39 Balashov, Y.: "Should Plato's line be divided in mean and extreme ratio?" en "Ancient Philosophy", Mathesis Publications, 1994 y Gaiser, K.: op. cit., pp. 149-152.
} 
receptáculo) y participa de lo inteligible de una manera particularmente paradójica y difícil de comprender. En efecto, a través de esta analogía, según mi opinión Platón no quiere decir que el alma cósmica esté fabricada materialmente con el «oro», sino que las figuras geométricas que la componen reciben algunas propiedades o características matemáticas específicas: es decir, «áureas». 40 Estaríamos hablando, en efecto, de la fabricación del alma del cosmos que, en el Timeo, adopta la forma geométrica más perfecta: la del dodecaedro pitagórico o la esfera de los doce pentágonos. 41 De acuerdo con la física presocrática, en efecto, Platón afirma que el cosmos posee un cuerpo que se compone de cuatro elementos: fuego, aire, agua y tierra. El fuego permite al mundo ser visible, mientras que la tierra le posibilita que sea tangible. Por su parte, el aire y el agua sirven de intermediarios a los dos otros elementos, con el fin de producir un cuerpo tridimensional que obtiene su cohesión de una proporción geométrica o alma del cosmos. El alma del cosmos, fabricada por el demiurgo, posee entonces una determinada estructura matemática y está dotada de un movimiento circular. Además, por participar del ser y del devenir, el alma se convierte en el agente mediator entre las formas inteligibles eternas y el mundo sensible en movimiento. De manera que el alma del mundo representa el principio de movimiento y el principio del orden de ese movimiento, es decir, configura geométricamente la materia en el espacio. Platón asocia, en efecto, a cada uno de los cuatro elementos materiales del cosmos uno de los poliedros regulares (inscribibles en una esfera): tetraedro, cubo, octaedro e icosaedro, respectivamente, y el quinto poliedro, el dodecaedro, lo asocia al cosmos o universo, por ser el que más se aproxima a la esfera. ${ }^{42}$ Ahora bien, la característica más relevante del dodecaedro, que representa el orden matemático instaurado por el demiurgo, es que está construido según la proporción áurea. Gaiser, de acuerdo con el testimonio de Plutarco, explica efectivamente que la creación del cosmos por parte del Demiurgo - es decir, la producción de un orden en el ámbito intermedio entre las Ideas y los elementos materiales del cosmos- es paragonada a un problema específico de construcción matemático-geométrica: de lo que se trata, en definitiva, es establecer una relación proporcional entre las dos figuras geométricas que corresponden a la materia y a la forma del cosmos, de manera que el medio geométrico sea una parte del

\footnotetext{
40 Cornford, F.M.: Plato's Cosmology, Routledge \& Kegan Paul, London, 1971.

41 El hecho de que la propiedad o ratio específica del dodecaedro pitagórico sea la proporción áurea, o la división en media y extrema razón, es algo que explicaría también porque Platón haya cortado la línea del horizonte siguiendo la misma proporción. En efecto, el número phi $\varphi$ es la razón esencial de las proporciones del pentágono regular y, por lo tanto, de todas las de su ampliación en las tres dimensiones del dodecaedro (como en los dos sólidos estrellados que se obtienen prolongando las caras o las aristas de éste). Véase también Euclides: Elementos, Madrid, Gredos, 2008, Libro XIII, Proposición 17.

42 Véase, al respecto, la Introducción de Plátón, Timeo, Madrid, Abada Editores, 2010, edición bilingüe de José María Zamora Calvo, notas y anexos de Luc Brisson.
} 
todo. La conclusión es que para ordenar, relacionar o incluir a cada uno de los cuatro elementos materiales en una única totalidad cósmica es necesaria la mediación de la proporción continua. 43 Algébricamente, podemos formar una proporción continua partiendo solamente de dos cantidades A y B; su suma sería el tercer término y así obtendríamos la proporción más característica o continua por excelencia $(\mathrm{A}+\mathrm{B}): \mathrm{A}=\mathrm{A}: \mathrm{B}$. Aplicada a la geometría lineal, esta proporción corresponde a lo que Euclides llama, en el libro VI de sus Elementos, división en media y extrema razón -o proporción áurea- que es la división asimétrica más lógica y más importante por sus consecuencias aritméticas, geométricas, arquitectónicas, estéticas, éticas, ontológicas y cosmologícas: "Se dice que una línea recta ha sido cortada en extrema y media razón, cuando la recta entera es al segmento mayor como el segmento mayor es al menor". Dividir una línea $\mathrm{AB}$ en proporción áurea significa, en efecto, dividirla en dos segmentos de manera que el mayor sea la media proporcional entre el menor y el total o, lo que es lo mismo, que el menor sea la tercera proporcional entre el total y el mayor. Esto es hacer una «partición aditiva»: en efecto, una línea $\mathrm{AB}$ dividida en media y extrema razón $(\mathrm{AC}$ y $\mathrm{CB}$ ) da como resultado que el segmento total es a la parte mayor como la parte mayor es a la menor: $(\mathrm{AC}+\mathrm{CB})$ : $\mathrm{AC}=\mathrm{AC}: \mathrm{CB}=\Phi$, es decir $(1+0,618): 1=1: 0,618=$ número $\Phi$ 1,618 = el número áureo. Es decir, lo que refleja la proporción es precisamente una relación de igualdad entre el todo y sus partes. Ahora bien, como ya se ha dicho, el cosmos visible descrito en el Timeo es ordenado según la proporción áurea. Con doce pentágonos regulares, veinte números de vértices y doce números de caras el demiurgo construye un sólido geométrico -el dodecaedro- que representa precisamente el alma cósmica, lo cual confirmaría desde el punto de vista geométrico y cosmológico la hipótesis central de este trabajo. Desde el punto de vista axiológico, además, la proporción áurea representaría la medida o ley divina de la justicia con la cual antes Cronos, ${ }^{44}$ y después Zeus, rigen mitológicamente el universo: es decir, la Igualdad proporcional entre el todo del Universo y sus partes, o el Bien. Mientras

\footnotetext{
43 Gaiser, K.: op. cit., p. 74.

44 Es significativo que Platón haya ilustrado la idea de justicia política anclada cósmico-teológicamente a través del mito de Cronos, el dios que gobernó en la «edad de oro». En ella, nos narra el extranjero en el Político, los humanos eran inmortales, vivían junto con los dioses, observando la justicia y sin devorarse los unos a los otros. Según el mito, en efecto, el universo es algo compuesto de cuerpo y alma y, en tanto que creado y sometido al cambio, conoce dos tipos de movimiento: unas veces marcha conducido por una especial causa divina (la justicia) y otras queda abandonado a sí mismo (es decir, a la desmesura). En el primer periodo Cronos dirige la marcha del mundo y todo discurre con suavidad, sin guerras ni discordias. Sin embargo al final del periodo dorado, Cronos abandona el timón y deja el mando a merced del impulso contrario de la hýbris. En este instante se pasa a la situación inversa, puesto que comienza a tomar preponderancia la parte material del cosmos y se inicia un periodo de destrucción, guerras y calamidades. En efecto, todos los dioses subordinados a Cronos abandonan las partes del mundo que están a su cuidado generando un enorme desorden.
} 
que, desde el punto de vista ético-político, y volviendo al tema central de la justicia política, es probable que Platón haga referencia precisamente a la «divina proporción» a la hora de indicar la justa distribución de los bienes entre los ciudadanos. En el largo fragmento de Las Leyes citado anteriormente (nota $\mathrm{n}^{\circ}$ 9), en efecto, al hablar de la más auténtica y más excelente igualdad que nace del juicio de Zeus (la igualdad geométrica o proporcional frente a la aritmética), Platón explica que existe una «medida divina» que, a pesar de ser siempre constante y pequeña, cuando se aplica a la justicia política lo que produce es todo bueno; y eso porque cuando se dividen los bienes, es decir las riquezas y los honores, según esta medida se "otorga más al que es mayor y menos al que es menor, dando a cada uno lo adecuado a su naturaleza; $y$ también en cuanto a distinciones, concediéndoselas siempre mayores a los más excelentes en punto a virtud y al contrario a los que son de manera distinta por lo que toca a virtud y educación, distribuye proporcionalmente lo conveniente por cada cual". En esto consiste, precisamente, la más excelente justicia distributiva platónica: dar a cada cual lo adecuado "proporcionalmente» a su naturaleza, lo cual no es fácil para cualquiera el dilucidarlo.

Para concluir, de acuerdo con el enfoque etimológico de Cornford, Palmer y Gagarin entre otros, el significado esencial del término dikē hace referencia más que a una moralidad entendida genéricamente al procedimiento legal como sistema pacifico de resolver las controversias y restablecer la concordia o igualdad proporcional entre los dos contendientes, lo cual se expresaba antiguamente trazando una imaginaria «línea divisoria» entre ellos. Un estudio más preciso sobre la etimología de la palabra revela, además, la conocida conexión entre la metafísica, la cosmología y la epistemología de Platón al destacar la procedencia del término díke de la raíz sánscrita diś-(dik) que indica el concepto astronómico de «línea del horizonte» que separa aparentemente la unidad del cosmos en dos regiones opuestas (la tierra del cielo) para luego reunificarlo a través de la proporción geométrica -o la medida divina que gobierna todas las cosas-, restableciendo así la armonía o igualdad proporcional entre el todo y las partes.

\section{Referencias bibliográficas}

AA.VV:: The Cambridge History of Classical Literature, Cambridge University, Easterling and B. M. Knox, 1985.

Aristóteles: Ética a Nicómaco, Madrid, Centro de Estudios Políticos y Constitucionales, 2002.

ARIstóteles, Acerca del alma, Traducción de Tomás Calvo, Madrid, Gredos, 1988, Balashov, Y.: Should Plato's line be divided in mean and extreme ratio?" en “Ancient Philosophy”, Mathesis Publications, 1994. 
BeArzot, C.: La giustizia nella Grecia antica, Roma, Carocci, 2011.

Benveniste É.: Vocabulario de las instituciones indoeuropeas, Madrid, Taurus, 1983.

Bonner, R. J.: The Administration of Justice from Homer to Aristotle, New York, Greenwood Press, 1968.

Brisson, L.: Le Même et l'Autre dans la structure ontologique du "Timée" de Platon : un commentaire systématique du "Timée" de Platon, Sankt Augustin, Academia Verlag, 1998.

Chantraine, P.: Dictionnaire étymologique de la langue grecque: histoire des mots, Paris, Klincksieck, 1990.

CORnFord, F. M.: De la religión a la filosofía, Barcelona, Ariel, 1985.

CORnFord, F.M.: La teoría platónica del conocimiento, Paidós, Buenos Aires, 1991.

Cornford, F.M.: Plato's Cosmology, Routledge \& Kegan Paul, London, 1971.

Del Vecchio, G.: La giustizia, Roma, Studium, 1946.

DüMmLer, F.: Prolegomena zu Platons Staat, Basilea, 1891.

Escuela Bíblica de Jerusalén: Biblia de Jerusalén, Bilbao, Desclée de Brouwer, 1988.

Gagarin, M.: Dike in the Works and Days, en "Classical Philology", Vol. 68, N², 1973.

GAISER, K.: La dottrina non scritta di Platone. Studi sulla fondazione sistematica e storica delle scienze nella scuola platonica, Milán, Vita e Pensiero, 1994.

HARris, E. M.: Democracy and the Rule of Law in a Classical Athens, New York, Cambridge University, 2006 .

Harrison, J.: Themis, Cambridge, University Press, 1912.

Harrison, J.: Prolegomena to Study of Greek Religion, Cambridge, University Press, 1903.

Hirzel R.: Temis, Dike und Verwandtes, Hildesheim, Georg Olm, 1968.

HöSLE, V.: I fondamenti dell'aritmetica e della geometria in Platone, Milano, Vita e Pensiero, 1994.

Jellamo, A.: Il cammino di Dike L'idea della giustizia da Omero a Eschilo, Roma, Donzelli, 2005.

KaHn, Ch. H.: The Art and Thought of Heraclitus, Cambridge, Cambridge University Press, 1979.

Kramer. H.: Platone e i fondamenti della metafisica. Saggio sulla teoria dei principi e sulle dottrine no scritte di Platone, Milano, Vita e Pensiero, 2001.

MacDowell, D.M.: The Law in Classical Athens, New York, Cornell University Press, 1978.

Mas Torres, S.: Ethos y Pólis. Una historia de la filosofía práctica en la Grecia clásica, Madrid, Istmo, 2003. 
MonIER, W. M.: A Sanskrit English dictionary etymologically and philologically arranged with special reference to cognate indo-European languages, Oxford, Clarendon Press, 1964.

Oncina Coves, F.: Teorías y prácticas de la historia conceptual, Madrid, Consejo Superior de las Investigaciones Científicas, 2009.

Onians, R.B.: Le origini del pensiero europeo, Milano, Adelphi, 1998.

PAlmer, L. R.: The Indo-European Origins of Greek Justice, en "Transactions of the American Philological Society", Vol. 49, 1950.

Platón: La Leyes, Madrid, Centro de Estudios Políticos y Constitucionales, 1999.

Plátón, Timeo, Madrid, Abada Editores, 2010.

Platón: La República, Madrid, Centro de Estudios Políticos y Constitucionales, 2006.

Pseudo-Calístenes: Vida y hazañas de Alejandro de Macedonia, Madrid, Gredos 1988.

Reale, G.: Per una nuova interpretazione di Platone, Milano, Vita e Pensiero, 2003.

RENDICH, F.: Dizionario etimologico comparato delle lingue classiche indoeuropee, Roma, Palombi, 2010.

Salamone, M.A.: La Ética y la Política de Aristóteles: una cuestión de proporciones áureas, Milán, Lampi di Stampa, 2007.

Sealey, R.: The Justice of the Greek, Michigan, University of Michigan Press, 1994.

Tomas de Aquino: Suma Teológica, Tratado de la Justicia, Madrid, Biblioteca de Autores Cristianos, 1956, Tomo VIII.

Vernant, J.P. : Pandora, la première femme, Paris, Bayard, 2006.

VERNANT, J.P. : Los orígenes del pensamiento griego, Barcelona, Paidós, 2011.

Maria Antonietta Salamone

Departamento de Filosofía del Derecho, Moral y Política II

Universidad Complutense de Madrid

salamonema@filos.ucm.es 